\title{
Artesunate Loaded Self Nanoemulsified Drug Delivery System: A Preliminary Study for Improved Efficacy in the Treatment of Malaria: Formulation, Characterization and Bio-Distribution Study
}

\section{Suresh Kumar $\mathbf{R}^{*}$}

Department of Pharmaceutics, JSS College of Pharmacy, Ootacamund, Tamil Nadu 643001, India

\begin{abstract}
The current study focused on formulation and evaluation of Artesunate loaded Self Nanoemulsified Drug Delivery System (SNEDDS). The research oriented towards the establishment of the pharmacokinetic parameters and biodistribution of Artesunate for SNEDDS. Artesunate nanoemulsion were developed using lipid, surfactant and Co Surfactant respectively (Capryol 90, Cremophor EL and Ethanol) by Spontaneous emulsification method. The investigation includes various characterization studies viz., particle size distribution, poly dispersibility index, zeta potential, viscosity, refractive index, \% transmission and conductivity. The results were found to be $110.4 \mathrm{~nm}, 0.386$, $-36.6 \mathrm{mV}, 19.54 \mathrm{cps}, 1.287,100,367.2 \mu \mathrm{S} / \mathrm{cm}$ respectively with the optimized formulation 5 . The in vitro drug release of Artesunate from SNEDDS formulation for was extremely significant when compared to pure drug suspension and the marketed formulation. The maximum release of drug from SNEDDS, marketed formulation and pure drug suspension was $98.78 \%, 62.78 \%$ and $20.88 \%$ respectively. The pharmacokinetic parameters of $C_{\max }, \mathrm{AUC}_{(0-2 \mathrm{~h})}$, AUC $_{(0)}, \mathrm{Kel}, \mathrm{T}_{\mathrm{max}}$ and MRT were found to be $2467 \pm 11.98 \mathrm{ng} / \mathrm{ml}, 1278 \pm 0.18 \mathrm{~h} . \mathrm{ng} / \mathrm{ml}, 3278 \pm 0.78 \mathrm{~h} . \mathrm{ng} / \mathrm{ml}, 1.04 \pm$ $0.07 \mathrm{~h}-1,1.0 \mathrm{~h}$ and $1.87 \pm 0.01 \mathrm{~h}$, respectively. From biodistribution studies the concentration of dihydroartemisinin (metabolite of Artesunate) was found to be maximum in the order of liver $>$ lung $>$ kidney $>$ spleen $>$ brain $>$ heart. The highest concentration of $1951.8 \mathrm{ng} / \mathrm{g}$ was found to be in the liver.
\end{abstract}

Keywords: Artesunate; Dihydroartemisinin; Self-Nanoemulsifying drug delivery; Bio-distribution

\section{Introduction}

In the present context, the failure of the conventional delivery system due to various factors like problems associated with absorption, altered metabolism, poor drug solubility, variability in plasma drug concentration and the effect of food, has given rise to the search for newer methods in case of delivery of a drug through oral route [1]. For improving the bioavailability and solubility of such oral drug delivery system, it is required to formulate suitable formulations. The main challenge for the formulation scientist has been the formulation and development of poorly water soluble moieties [2-5]. The lipid based formulation methodology has seen wide range of interest in improving the oral bioavailability and the drug solubilisation in the Gastrointestinal Tract (GIT) of BCS class II and IV drugs [6-9]. Current investigations support the usage of lipid based formulations to tackle the formulation challenges of poorly soluble drugs. There has been a considerable growth in the past 15 years on Lipid Based Drug Delivery System (LBDDS) as novel drug delivery system to deals with the problem associated with low solubility and high permeability (BCS Class II) [10] in case of wide range of new chemical moieties. Common pharmaceutical excipients used in self-nano emulsifying drug delivery system (SNEDDS) containing bio enhancers like cremophor, tween 80 are reported to facilitate absorption by inhibiting glycoprotein efflux hence enhancing the bioavailability [11]. Malaria is an acute infectious disease caused by the bite of female Anopheles mosquitoes belongs to genus Plasmodium which flies high in humid and swampy areas. Being the most insidious species, Plasmodium falciparum is rapid fulminating disease, the symptoms of which are persistent high fever, orthostatic hypotension, and massive erythrocytosis. Plasmodium falciparum infection can lead to capillary occlusion thereby causing death if treatment is not initiated promptly. Plasmodium vivax causes a mild form of malaria, Plasmodium malariae is most common in tropical regions and Plasmodium ovale is often encountered. The resistance acquired by the by the parasite to drugs, abstained for the development of new therapeutic challenges, particularly in the controlling of resistance caused by P. falciparum [12]. The efficacy of a drug treatment particularly to plasmodium species and each stage of its life cycle is being targeted. The main objectives of anti-malarias are to prevent and treat patient suffering from malaria and also complete eradication of the parasite from the body [13]. The main aim of the research was to find out the enhancement of bioavailability by loading artesunate with poor bioavailability in nano-emulsion (Nanodroplets) formulated with various components like lipid, Surfactant and Co Surfactant (SCoS), using spontaneous emulsification method (Aqueous titration method).

\section{Materials and Method}

\section{Materials}

Artesunate (complementary sample) obtained from Mylan laboratories, Ltd., (Hyderabad, India).

Capryol 90 was purchased from gatteffosse India Pvt. Ltd. (Mumbai,

*Corresponding author: Suresh Kumar R, Professor, Department of Pharmaceutics, JSS College of Pharmacy, Ootacamund, Tamil Nadu 643001, India Tel: +919865064872; E-mail: sureshcoonoor@yahoo.com

Received February 23, 2017; Accepted March 03, 2017; Published March 10, 2017

Citation: Kumar SR (2017) Artesunate Loaded Self Nanoemulsified Drug Delivery System: A Preliminary Study for Improved Efficacy in the Treatment of Malaria: Formulation, Characterization and Bio-Distribution Study. J Bioequiv Availab 9: 364371. doi: $10.4172 / \mathrm{jbb} .1000326$

Copyright: (c) 2017 Kumar SR. This is an open-access article distributed under the terms of the Creative Commons Attribution License, which permits unrestricted use, distribution, and reproduction in any medium, provided the original author and source are credited. 
India). Cremophore EL brought from sigma Aldrich Corporation, (Bangalore). Ethanol purchased from Merck chemicals India Pvt. Ltd. (Mumbai). The chemical used in the research was analytically graded.

\section{Solubility studies}

Solubility of artesunate was found in different oils through (Shake flask method) [14] through the addition of an excess quantity of drug to $2 \mathrm{ml}$ of oil in volumetric flasks. The temperature of flasks was maintained at $25 \pm 0.5^{\circ} \mathrm{C}$ using an isothermal shaker (IKA ${ }^{\circ} \mathrm{KS} 4000 \mathrm{i}$, Germany) for time duration of $72 \mathrm{~h}$ for reaching equilibrium. The equilibrated sample remained detached from shaker and was centrifuged at $4000 \mathrm{rpm}$ for 15 min and filtration of supernatant was done by using $0.45 \mu \mathrm{m}$ membrane filter. Artesunate concentration in the supernatant was determined by using UV spectrophotometer.

\section{Screening of surfactant and Co Surfactant (SCoS)}

Screening of the surfactant and co surfactants was established by the formation of emulsion in the respective oil phase. The ability to emulsify was determined by mixing of oil phase, surfactant and aqueous phase to form a uniform emulsion [15].

\section{Purity and melting point of the drug}

A small quantity of sample was placed into a capillary fusion tube and sealed from one end with the help of the burner. The capillary tube was placed in the melting point determining apparatus (Capillary tube melting point apparatus) containing liquid paraffin. The temperature of the liquid paraffin was gradually increased and the temperature at which sample started to melt was observed and noted.

\section{Drug interaction studies by FTIR}

Compatibility of drug, lipid, Surfactant, Co Surfactant and formulation were studied using FTIR spectrophotometer (Shimadzu, Japan). A physical mixture of drug, lipid and surfactants (either alone or in combination) was prepared using anhydrous potassium bromide $(\mathrm{KBr})$ in 1:4 ratios. About $100 \mathrm{mg}$ of this mixture was ground into fine powder followed by compression using a hydraulic press at 15 tons, to form a thin transparent $\mathrm{KBr}$ pellet. Each $\mathrm{KBr}$ pellet was scanned at a resolution of $2 \mathrm{~cm}$ at $4 \mathrm{~mm} / \mathrm{s}$ of a wave number region from 4000 to $400 \mathrm{~cm}^{-1}$. The result of physical mixture was compared with pure drug, lipid, surfactant and matching of the IR peak was done to detect any appearance or disappearance of peaks [16].

\section{Formulation of artesunatenano emulsion (NE)}

Nanoemulsions were formulated by the spontaneous emulsifying method (Aqueous titration method). They were formulated basically by mixing of oil, water and surfactant Co Surfactant (SCoS), in correct ratio, followed by mild agitation. Nanoemulsion regions alone were constructed using Pseudo ternary phase diagrams [17].

\section{Construction of pseudo ternary phase diagrams}

The study was done to know the formation of oil in water $(\mathrm{o} / \mathrm{w})$ nanoemulsion with 4 components viz. Oil, surfactant, co-surfactant, and aqueous phase. Oil ratio was kept constant and different proportions of SCoS from 1:1 to 1:3 ratios in each group were mixed. Nine combinations of oil and SCoS, 1:1 to 1:9 were made to cover maximum ratios which represent phases outer boundaries formed in the phase diagram. For every weight ratio of oil and SCoS titration of water was performed. Transparency and flow ability of the NEs were observed visually. In the phase diagram, only the NE regions were plotted [18].

\section{Evaluation of nanoemulsion}

Thermodynamic stability studies: The formulations were exposed to the subsequent stability studies [19]. A. Heating and cooling cycle: Cooling cycle was done in refrigerator at $4^{\circ}$ Cand heating cycle was done in hot air oven at $45^{\circ} \mathrm{C}$ for $48 \mathrm{~h}$. The formulations in which no physical and chemical changes were observed and chosen for the centrifugation test. B. Centrifugation: Centrifugation study for the selected formulations was do neat $3500 \mathrm{rpm}$ for $30 \mathrm{~min}$. Formulations were subjected for the freeze thaw cycle in which no phase separation occurred. C. Freeze thaw cycle: Freeze thaw cycles were carried out in deep freezer where the formulation was stored at temperature of $-2^{\circ} \mathrm{C}$ and $+25^{\circ} \mathrm{C}$ around 48 $\mathrm{h}$. The formulations that passed the thermodynamic stability tests were studied further.

Particle size, zeta potential and polydispersity index (PDI): The determination of particle size and zeta potential of nanoemulsion were done by photon correlation spectroscopy with a Malvern Zetasizer Nano ZS90 at $25^{\circ} \mathrm{C}$. A proper dilution with samples was dispersed in preparation medium and placed in polystyrene cells for PDI measurement and disposable plain folded capillary zeta cells for zeta potential measurement [20].

Refractive index, \% transmittance, viscosity and conductivity: To determine the drug loaded formulations an Abbe-type refractometer (Macro Scientific Works, Delhi) was been used. The percentage transmittance of NE formulations was measured by using Shimadzu UV-Visible spectrophotometer. DVE viscometer (Brookfield Engineering Laboratories, Inc.,) was used to determine the viscosity of the formulation. Around $0.5 \mathrm{~g}$ of sample was reserved for analysis without dilution and the sample was analyzed by using spindle no. 63 at different rpm at $25 \pm 0.5^{\circ} \mathrm{C}$. Electro-conductivity of the resultant system was measured by an electro-conductometer and examined NEs were arranged with $0.01 \mathrm{~N}$ aqueous solution of sodium chloride instead of doubled distilled water. The measurements were done in triplicate at $25 \pm 1^{\circ} \mathrm{C}[21,22]$.

\section{In vitro release studies}

Drug loading was done based on the dose equivalent in $1 \mathrm{ml}$ of optimized nano emulsion. The in vitro drug release test was done in $250 \mathrm{ml} \mathrm{pH} 6.5$ biorelevant media using USP dissolution apparatus Type I at $50 \mathrm{rpm}$ at $37 \pm 5^{\circ} \mathrm{C}$ for quantitative analysis. The optimized SelfNano Emulsifying Drug Delivery System (SNEDDS) (Preconcentrate) containing single dose of Artesunate in oil and SCoS was filled in capsule size 2. At each interval of time $0,0.5,1,1.5$, and $2 \mathrm{~h}$ samples were withdrawn with the substitution of equal amount of dissolution media. Samples were filtered and analyzed in UV-Spectrophotometer at $210 \mathrm{~nm}$. The release of drug from SNEDDS formulation was also compared with the conventional tablet and pure drug suspension [23].

\section{In vivo pharmacokinetic study}

The experiments were carried out after getting the approval of the CPCSEA and IAEC, from JSS College of Pharmacy, Ooty. Reg. No: JSSCP/IAEC/M.PHARM/PH.CEUTICS/02/2014-15. CPCSEA and their guidelines were followed throughout the experiment.

\section{HPLC Method}

The HPLC system consist of a mobile phase delivery pump (LC-20 AD; Shimadzu, Japan), a photodiode array (PDA) detector (SPDM20 A; Shimadzu, Japan) and a $20 \mu \mathrm{L}$ loop (Rheodyne). A C18 reversephase column (Phenomenex Gemini C18, $250 \times 4.6 \mathrm{~mm}$ i.d., $5 \mu$ ) was used for drug separation. The estimation of drug content was analyzed 
using a mobile phase acetonitrile: $50 \mathrm{mM}$ potassium dihydrogen orthophosphate $\mathrm{pH} 4.8(50: 50, \mathrm{v} / \mathrm{v})$, at the $1.0 \mathrm{ml} / \mathrm{min}$ and $\mathrm{UV}$ wavelength at $210 \mathrm{~nm}$ [24].

\section{Estimation of drug in rat plasma}

Healthy Male Sprague-Dawley rats, fasted overnight, with a weight of about 250-300 g were used for in vivo experiment. The animals were provided with water and libitum in fasting and during the experimentation. Early in the morning zero periods fasting blood samples were withdrawn. The animals were then categorized into 4 groups, every group having three animals $1.25 \mathrm{mg} / \mathrm{kg}$ dose administered based on the surface area ratio of rat and man through oral gavage. Group 1 was given conventional marketed formulation, group 2 was given SNEDDS formulation, group 3 was given pure drug suspension and group 4 were used as control which was used for plasma spiking. $0.5 \mathrm{ml}$ of blood samples was withdrawn from the Retro orbital puncture with a Capillary tube at $0,15,30,45,60,90,120 \mathrm{~min}$. The blood samples were collected in a RIA vial containing anti-coagulant $(0.4 \mathrm{ml}$ of $2.5 \%$ sodium citrate), centrifuged at $4000 \mathrm{rpm}$ for $5 \mathrm{~min}$ and the plasma samples were separated and stored at $-20^{\circ} \mathrm{C}$. Deprotonation of the plasma samples were carried out and the drug was extracted by protein precipitation method using methanol and then analyzed by HPLC. One way ANOVA method was used for predicting the significant difference using Graphpad Prism software [25,26].

\section{Pharmacokinetic data analysis}

Non-compartmental analysis of the individual concentration-time data using PhoenixWinNonlin v6.3 software (Pharsight Corporation, Mountain view, CA, USA) was performed for the calculation of pharmacokinetic parameters. The pharmacokinetic parameters viz., maximum plasma concentration $\left(\mathrm{C}_{\max }\right)$ and the time to reach $\mathrm{C}_{\max }$ $\left(\mathrm{T}_{\max }\right)$ were obtained directly from the plasma concentration-time curve. The elimination rate constant (Kel) was obtained from the leastsquares fitted terminal log-linear portion of the plasma concentrationtime profile, and area under the plasma concentration time curve from 0 to $2 \mathrm{~h}\left(\mathrm{AUC}_{0-2 \mathrm{~h}}\right)$ was obtained by the linear trapezoidal rule, and area under the curve from $0 \mathrm{~h}$ extrapolated to infinity ( $\mathrm{AUC}_{0}$ $\left.{ }_{\infty}\right)$ was calculatedas $\mathrm{AUC}_{0-2 \mathrm{~h}}+\mathrm{CT} / \mathrm{Kel}$ where $\mathrm{CT}$ signifies the plasma concentration at the last measurable sampling time [27].

\section{Biodistribution studies}

Same animals were used after a wash out period of 2 months. The animals were taken care of according to CPCSEA guidelines. The animals were provided using food and water ad libitum and fasted for 12 $\mathrm{h}$ prior to the commencement of the experiment. The tissue distribution studies were performed, immediately after cervical dislocation; the organs (heart, liver, spleen, lung, kidney and brain) were collected. The isolated tissues were placed in normal saline solution to remove blood content and blotted dry with tissue paper. The isolated organs were further crushed individually with the help of triple blade stirrer and centrifuged at $10000 \mathrm{rpm}$ for $10 \mathrm{~min}$. The supernatant solutions were collected and stored at $-70 \pm 2^{\circ} \mathrm{C}$ for drug content analysis [28].

\section{Results and Discussions}

\section{Solubility studies of drug in various oils}

Solubility is an important parameter in the formulation of SNEDDS, where drug remains in liquid which solubilized in the oil phase. For solubility study, the oil phase in which the drug showed highest concentration was selected. The evidence from Figure 1 showed

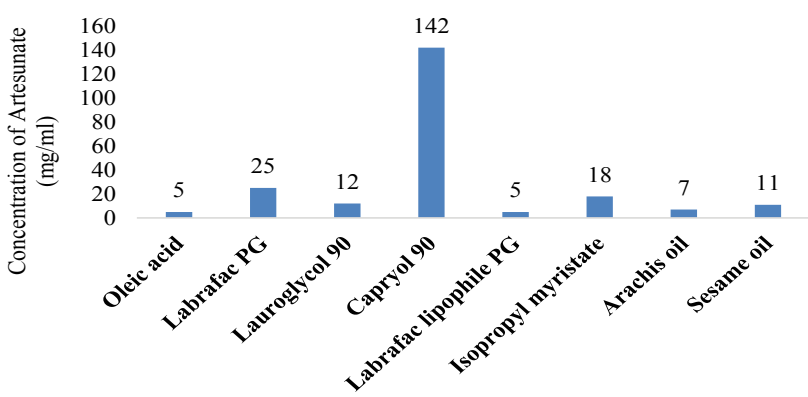

Figure 1: Solubility studies.

that capryol 90 has maximum solubility of artesunate $142 \pm 0.54 \mathrm{mg} / \mathrm{ml}$. Hence for the formulation of SNEDDS, capryol 90 was selected. Due to the more affinity of drug towards the respective oil solubility of the drug has been increased.

\section{Screening of surfactants and co-surfactants}

From the screening studies, the SCoS mixture of cremophor EL and ethanol for capryol 90 were found to produce clear and uniform $\mathrm{o} / \mathrm{w}$ emulsion. Hence, cremophor EL and ethanol were selected for the formulation. The selected SCoS mixture was found to produce a clear and uniform emulsion with capryol 90.

\section{Purity and melting point of the drug}

The Merck Index states that Artesunate melts at about $135-137^{\circ} \mathrm{C}$. The melting point of Artesunate observed was $136.33^{\circ} \mathrm{C}$, which states that the sample complies to be pure with no impurities.

\section{Drug interaction studies by FTIR}

From the obtained FTIR studies it was seen that there were no drug interactions with the excipients. The prominent peaks in artesunate spectra as follows $2883 \mathrm{~cm}^{-1}$ to CH stretching vibration, $3000-3500 \mathrm{~cm}^{-1}$ to $\mathrm{OH}$ stretching vibration, $1755 \mathrm{~cm}^{-1}$ to $\mathrm{C}=\mathrm{O}$ stretching vibration and $1212 \mathrm{~cm}^{-1}$ to $\mathrm{C}-\mathrm{O}$ stretching vibration. The functional groups along with corresponding peaks of pure artesunate and in physical mixture of artesunate were no interactions between artesunate and selected Oil+SCos. Hence, pure dug and physical mixture of excipients are compatible with each other.

\section{Pseudo ternary phase diagram study}

By constructing phase diagrams, phase behavioural studies were performed which represents the boundaries of dissimilar phases, arrangements and to examine the structural organization of the emulsions formed. To prevent the coalescence of the designed NE by the concentration of surfactant and co-surfactant this is responsible for forming the barrier at the interface. To improve the thermodynamic stability of the NE formulation, the SCoS should be adsorbed at the crossing point, thus decreasing the energy required for NE formation. Among all ratios from 1:1 to 1:3 in SCoS ratio 1:1 produced the clear solution of Oil and SCoS of 1:5, 1:6, 1:7, 1:8 and 1:9 these formulations covered the most of the nano-emulsion area and those formulations were selected for the further studies. The optimized formulations ternary phase diagram shown in Figure 2.

\section{Formulation selection of artesunate NE Oil phase Capryol 90 , SCoS: Cremophor EL and Ethanol}

Different concentration of oil, which solubilize single dose of drug 


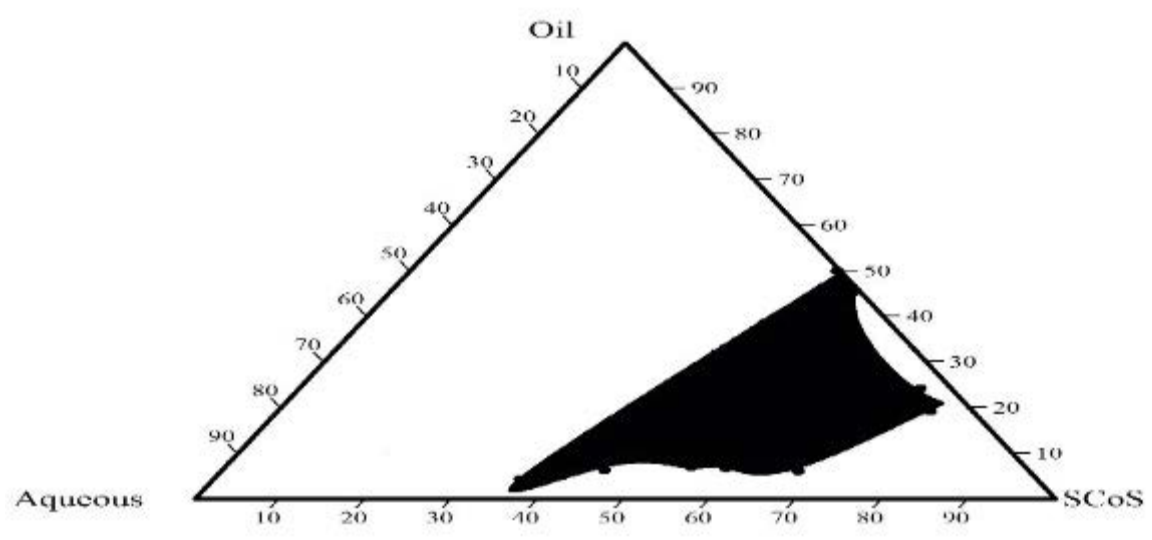

Figure 2: Ternary phase diagram of optimized formulation 5.

were selected at $5 \%$ intervals $(10 \%, 15 \%, 20 \%, 25 \%$ and $30 \%)$ from each phase diagram, so that, largest number of formulations could be selected which covers the nanoemulsion area of the phase diagram. Only individual formulations were selected having least concentration of SCoS for forming nanoemulsion. The results were shown in Table 1. The optimization was done and the drug was dissolved in the respective oil and mixed with SCoS to form self-emulsifying concentrate. Since the solubility of the drug was well above to the dose, the total amount of drug was assumed to be present in the oil phase.

\section{Evaluation of NE}

Thermodynamic stability studies: The formulations which are been selected from the pseudo ternary phase diagram with ratio of SCoS 1:5, 1:6, 1:7, 1:8 and 1:9 were subjected to various thermodynamic stability studies. The nanoemulsion that are kinetically stable and undergo phase-separation that was differentiated by thermodynamic stability studies. This indicates the formulations comprise adequate quantity of SCoS concentration which is needed for NE formulation, which declines the energy necessary for NE formation. Hence, the stability of NE is due to decrease in energy. The entering of NE through the GI tract, it undergoes infinite dilution leading to phase separation because of poor dispersibility. By dispersing in the aqueous milieu of the GIT formulations which conceded the dispersibility studies can certain to remain as NE. The dilution of the oral NE through the GI fluids will result in the gradual desorption of the surfactant located at the globule interface. From the Table 2 all formulations which passed the thermodynamic stability test and dispersibility test were undergone for the investigation of globule size, zeta potential, \% transmission, viscosity, refractive index and PDI analysis. Formulations, which are clear and prevented from turbidity are considered as stable, whereas others are considered to be unstable.

Characterization studies: The increase in concentration of oil in the formulation globule size increases and decreases with increase in the SCoS concentration. Among the formulations which passed the thermodynamic stability tests, formulation 5 was found to have a mean globule size of $110.4 \mathrm{~nm}$ with a PDI 0.386 , and zeta potential $-36.6 \mathrm{mV}$ with $100 \%$ transmission was selected as the optimized formulation, subsequently other formulations mean droplet size and PDI were found to be larger than formulation 5 and wider range of particle size distribution which is not desirable. The other parameters for all the formulations were found to be good. Based on least mean particle

\begin{tabular}{|c|c|c|c|c|c|c|c|c|c|}
\hline SCoS & \multicolumn{10}{|c|}{ Oil: SCoS } \\
\hline \multirow{2}{*}{$1: 1$} & $1: 1$ & $1: 2$ & $1: 3$ & $1: 4$ & $1: 5$ & $1: 6$ & $1: 7$ & $1: 8$ & $1: 9$ \\
\cline { 2 - 11 } & E & E & E & E & NE & NE & NE & NE & NE \\
\hline \multirow{2}{*}{$1: 2$} & $1: 1$ & $1: 2$ & $1: 3$ & $1: 4$ & $1: 5$ & $1: 6$ & $1: 7$ & $1: 8$ & $1: 9$ \\
\cline { 2 - 11 } & M & E & E & EG & E & M & E & NE & NE \\
\hline \multirow{2}{*}{$1: 3$} & $1: 1$ & $1: 2$ & $1: 3$ & $1: 4$ & $1: 5$ & $1: 6$ & $1: 7$ & $1: 8$ & $1: 9$ \\
\cline { 2 - 10 } & E & E & M & EG & EG & E & EG & E & M \\
\hline
\end{tabular}

NE: Nanoemulsion; E: Emulsion; EG: Emulsion gel; M: Milky

Table 1: Visual observation during aqueous phase titration for formulation selection by using SCoS ratio $1: 1$ to $1: 3$.

size the optimized formulation was selected and PDI. The additional parameters like viscosity, refractive index and conductivity were found to be acceptable for all the formulations. The results were mentioned in the Table 3. Since the formulations are translucent, $\%$ transmission is almost maximum which is also supported by refractive index. The PDI was also very minimum shows the droplets are uniformly distributed and zeta potential was found to be $-36.6 \mathrm{mV}$, due to presence of free fatty acid which shows that the formulation is stable. From the Figures 3 and 4 shown, the formulation 5 was selected for drug loading and in vivo and in vitro studies.

\section{Drug loading}

The optimized formulation 5 was been selected for the drug content analysis. Since the solubility of the drug in oil was well above to the dose of the drug, capacity of oil phase used remained equivalent to the dose of the drug i.e., artesunate $50 \mathrm{mg}$, Oil and SCoS volume is $0.35 \mathrm{ml}$ and $0.2 \mathrm{ml}$ respectively.

\section{In vitro drug release}

In vitro dissolution studies were performed in $\mathrm{pH} 6.5$ biorelevant media for formulation 5 and compared with marketed and pure drug suspension. pH 6.5 was selected based on the literature support that which says that very short residence time of lipid based drug delivery systems in gastric $\mathrm{pH}$ and maximum absorption takes place in small intestine whose $\mathrm{pH}$ is 6.5 . The solubilisation of lipophilic molecule occurs at upper GI tract in which pancreatic fluids and biliary lipids are secreted which enhances solubilisation process. The residence time in upper GI is limited and the transit time in small intestine is 3.5 to $4.5 \mathrm{~h}$. Hence the pH 6.5 is used as a dissolution media. To investigate the drug 
Citation: Kumar SR (2017) Artesunate Loaded Self Nanoemulsified Drug Delivery System: A Preliminary Study for Improved Efficacy in the Treatment of Malaria: Formulation, Characterization and Bio-Distribution Study. J Bioequiv Availab 9: 364-371. doi: 10.4172/jbb.1000326

\begin{tabular}{|c|c|c|c|c|c|c|c|c|}
\hline Formulation & SCoS & \% Oil & \% CoS & \% Water & Heating and Cooling Cycle & Centrifugation & Freeze thaw Cycle & Dispersibility \\
\hline 1 & $1: 1$ & 1.49 & 16.84 & 6.7 & $\mathrm{P}$ & $\mathrm{P}$ \\
\hline 2 & $1: 1$ & 1.36 & 12.10 & 7.2 & $\mathrm{P}$ & $\mathrm{P}$ \\
\hline 3 & $1: 1$ & 1.31 & 10.4 & 7.4 & $\mathrm{P}$ & $\mathrm{P}$ \\
\hline 4 & $1: 1$ & 1.12 & 8.9 & 8.9 & $\mathrm{P}$ & $\mathrm{P}$ \\
\hline 5 & $1: 1$ & 0.84 & 7.6 & 11.8 & $\mathrm{P}$ & $\mathrm{P}$ & $\mathrm{P}$ \\
\hline
\end{tabular}

Note: P: Pass

Table 2: Thermodynamic stability studies (mean \pm S.D, $n=3$ ).

\begin{tabular}{|c|c|c|c|c|c|c|c|}
\hline Formulation & Mean Droplet Size (nm) & PDI & Zeta Potential (mV) & $\%$ Transmission & Viscosity (cps) & Refractive Index & Conductivity $(\mu \mathrm{S} / \mathrm{cm})$ \\
\hline 1 & 284.1 & 0.639 & -25.96 & 89.1 & 23.14 & 1.754 & 415.2 \\
\hline 2 & 219.25 & 0.964 & -22.07 & 97.2 & 28.78 & 1.687 & 397.5 \\
\hline 3 & 217.56 & 0.756 & -20.04 & 97.9 & 25.14 & 1.517 & 378.4 \\
\hline 4 & 227.39 & 0.807 & -23.08 & 94.9 & 24.78 & 1.487 & 348.8 \\
\hline 5 & 110.4 & 0.386 & -36.6 & 100 & 19.54 & 1.287 & 367.2 \\
\hline
\end{tabular}

Table 3: Physical characterization studies of nanoemulsion.

Results

$\begin{array}{rlllll} & & \text { Size (d.nm): } & \% \text { Intensity: } & \text { St Dev (d.n... } \\ \text { Z-Average (d.nm): } 110.4 & \text { Peak 1: } & 127.0 & 100.0 & 40.54 \\ \text { Pdl: } 0.386 & \text { Peak 2: } & 0.000 & 0.0 & 0.000 \\ \text { Intercept: } 0.917 & \text { Peak 3: } & 0.000 & 0.0 & 0.000\end{array}$

Result quality : Good

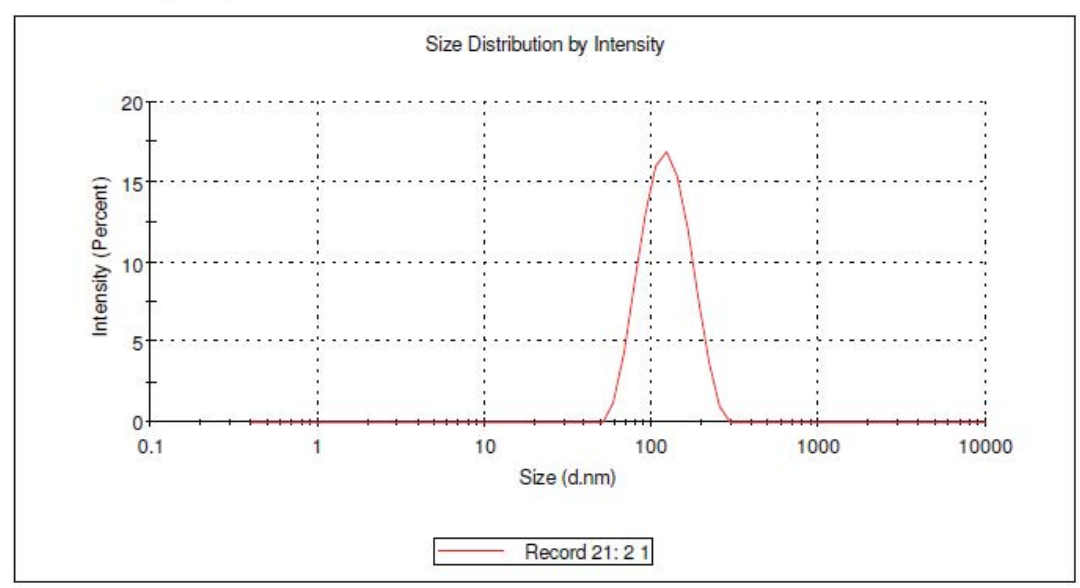

Figure 3: Size distribution report for optimized formulation 5.

dissolution from SNEDDS, marketed tablet formulation and pure drug suspension containing same quantity of drug, comparative dissolution studies were performed. In vitro dissolution studies indicated that Artesunate released an initial amount of $30.77 \%$ at 15 min for SNEDDS formulation, whereas the marketed formulation was $22.78 \%$ and for pure drug it was $10.78 \%$. The release rates were significant compared to both pure drug suspension and for marketed formulation. The reason for this could be the smaller droplet size and PDI, which lead to the increased surface area permitting a faster release rate with a maximum release within $90 \mathrm{~min}$. At the end of $120 \mathrm{~min}$ almost all the drug was found in solution. At the end of the study SNEDDS formulation did not show any precipitation or aggregation of the particles. The release profile shows that the SNEDDS preserved enhanced in vitro dissolution and which would eventually enhance dissolution of drug. Since the drug is low soluble only $20.88 \%$ of drug was released from pure drug suspension. Marketed formulation may contain some of the solubility enhancement formula hence artesunate of around $62.78 \%$ was found in solution, whereas the SNEEDS released around $98.78 \%$. Since the drug is available in droplet form and the formation is colloidal which could able to keep the drug in solution along micelles \& reverse micelles. The drug release from the SNEDDS formulation for Artesunate was extremely significant in comparison with the pure drug suspension and the marketed formulation. The results were shown in Figure 5.

\section{In vivo pharmacokinetic studies}

The in vivo release of artesunate in Sprague-Dawley rats for SNEDDS, marketed tablet and pure drug suspension were used to calculate the pharmacokinetic parameters. For the absorption of artesunate the rate limiting step was dissolution. The obtained result showed that the rate 
Citation: Kumar SR (2017) Artesunate Loaded Self Nanoemulsified Drug Delivery System: A Preliminary Study for Improved Efficacy in the Treatment of Malaria: Formulation, Characterization and Bio-Distribution Study. J Bioequiv Availab 9: 364-371. doi: 10.4172/jbb.1000326

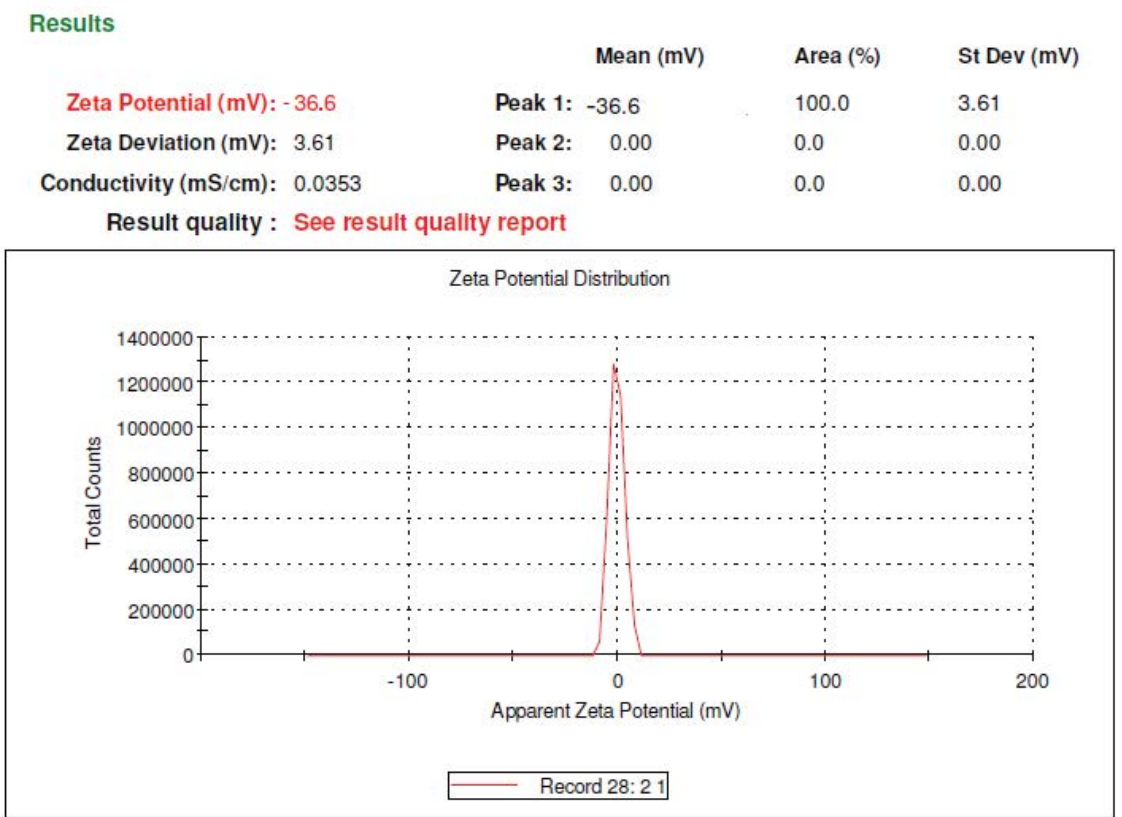

Figure 4: Zeta potential report for optimized formulation 5.

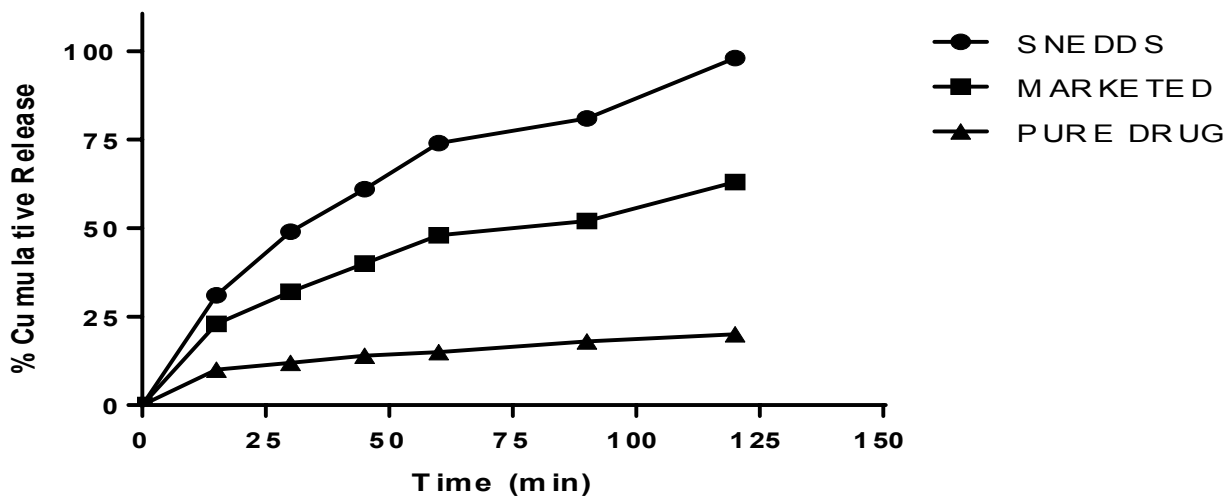

Figure 5: Comparison on \% cumulative release of SNEEDS, marketed conventional formulation and pure drug suspension.

\begin{tabular}{|c|c|c|c|}
\hline \multirow{2}{*}{ PK Parameters } & \multicolumn{2}{|c|}{ Dihydroartemisinin (DHA) } \\
\cline { 2 - 4 } & SNEDDS & Marketed & Pure drug suspension \\
\hline $\mathrm{C}_{\text {max }}(\mathrm{ng} / \mathrm{ml})$ & $2467 \pm 11.98$ & $1940 \pm 15.87$ & $640 \pm 0.34$ \\
\hline $\mathrm{T}_{\max }(\mathrm{h})$ & 2 & 3 & 5 \\
\hline $\mathrm{K}_{\mathrm{el}}(\mathrm{h}-1)$ & $1.01 \pm 0.07$ & $1.28 \pm 0.04$ & $1.50 \pm 0.14$ \\
\hline $\mathrm{AUC}_{(0-\mathrm{t})}(\mathrm{ng} \cdot \mathrm{h} / \mathrm{ml})$ & $6278 \pm 0.18$ & $3455 \pm 10.47$ & $1110 \pm 0.01$ \\
\hline $\mathrm{AUC}_{(0-\infty)}(\mathrm{ng} \cdot \mathrm{h} / \mathrm{ml})$ & $8478 \pm 0.78$ & $4240 \pm 0.55$ & $1540 \pm 0.27$ \\
\hline $\mathrm{MRT}(\mathrm{h})$ & $1.87 \pm 0.01$ & $1.46 \pm 0.02$ & $0.64 \pm 0.04$ \\
\hline
\end{tabular}

Table 4: Pharmacokinetic parameters of DHA after oral administration (mean \pm S.D., $n=3)(" p<0.05)$.

limiting step in case of SNEDDS was dispersion of the drug into the aqueous gastrointestinal environment and plays an important role in absorption. We can conclude that, on subsequent oral administration, SNEDDS dissolve spontaneously to arrange as NE in the GI fluid where the active components are present in a solubilized form, and the small droplet size offers a large surface area for drug absorption. According to the literatures, the oil will afford rapid and wide-ranging of absorption due to ultra-fine dispersion. The increase in the permeability of the oil across the cell membrane, and lymphatic transport was due to high concentration of surfactant in SNEDDS, due to which the formulation 


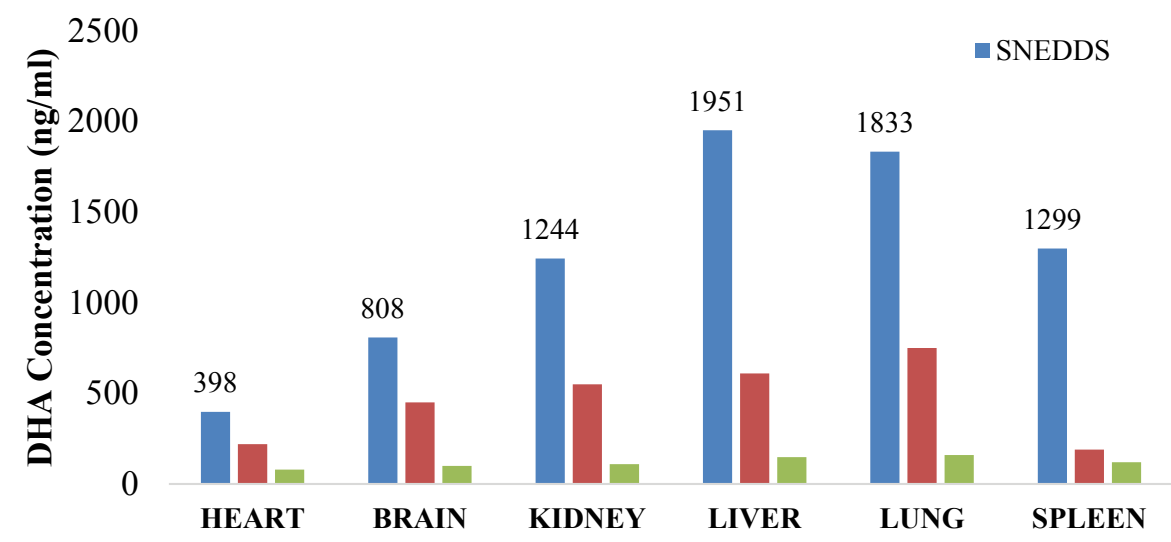

Figure 6: Comparison on biodistribution studies of SNEEDS, marketed conventional formulation and pure drug suspension.

takes around $2 \mathrm{~h}$ to achieve Tmax. Whereas the conventional marketed formulation did not show similar result, considering that it takes more time for disintegration and to go into the solution. Hence it took more than $2 \mathrm{~h}$ to achieve $\mathrm{T}_{\mathrm{max}}$, and moreover the extent of absorption which is evident fromAUC ${ }_{0-t}$ and $\mathrm{AUC}_{0-\infty}$, the SNEDDS achieved maximum plasma concentration, which is statistically significant. From the study it is evident that SNEDDS containing artesunate was well absorbed with a $\mathrm{C}_{\max }$ of $2467 \mathrm{ng} / \mathrm{ml}$ in $2 \mathrm{~h}\left(\mathrm{~T}_{\max }\right)$, whereas the marketed and pure drug suspension resulted in $1940 \mathrm{ng} / \mathrm{ml}$ in $3 \mathrm{~h}$ and $640 \mathrm{ng} / \mathrm{ml}$ in $5 \mathrm{~h}$ respectively. SNEDDS formulation had an elimination rate constant which is 1.01, 1.28 and 1.40 for SNEDDS, marketed and pure drug suspension respectively (The pharmacokinetic parameters were calculated by non-compartmental analysis of individual concentration-time data using Phoenix WinNonlin v 6.3 software (Pharsight corporation, Mountain view, CA, USA)). This may be due to the maximum concentration of drug enters the systemic circulation via lymphatics. The mechanism behind this may be the presence of fatty acids which triggered chylomicron synthesis in enterocytes in response to lipid digestion. The literature supports that Chylomicron consisting of triglycerides, surrounded by polar phospholipids and apoprotein, serves to solubilize the lipid in the aqueous environment of the blood that tends to drag lipids towards lymphatic system. Thus, enhances the bioavailability. This process also overcomes the presystemic metabolism. It is statistically evident since the statistical value of $\mathrm{P}<0.05$ was achieved with a significant of 0.0106 . This could be due to the fact that lipid droplets are taken by the chylomicrons. The results were mentioned in Table 4.

\section{Biodistribution studies}

Concentrations of dihydroartemisinin in DHA (metabolite of Artesunate) were been determined in various tissues like liver, spleen, heart, lung, brain and kidney of SD rats. The tissue distribution of Artesunate was analyzed by a non-compartment model and the results are showed in Figure 6. The concentration of DHA in all the collected tissues at $2 \mathrm{~h}$ were in the order of the maximum is, liver $>$ lung $>$ kidney $>\mathrm{s}$ pleen $>$ brain $>$ heart. The highest concentration of $1951.8 \mathrm{ng} / \mathrm{g}$ was found in the liver, which is more than 13 times that of pure drug and 3.19 times increase when compared with marketed formulation. Hence showed more significant on a $\mathrm{P}$ value of $0.0031(\mathrm{P}<0.05)$. This could be due to the fact lipid nanoemulsion is well taken by the reticuloendothelial system in association with the micelles and reverse micelles.

\section{Conclusion}

In conclusion, SNEDDS loaded Artesunate was been formulated for improving the pharmacokinetics of by the oral route. From the results it can be concluded that the SNEDDS formulation for the artesunate to contain oil phase Capryol 90 with Cremophor EL and ethanol as SCoS 1:1 mixture. The formulations exhibited nano droplet size with least PDI, \& stable zeta potential for formulation 5. The study also suggests that the SNEDDS formulation showed high bioavailability and rate of drug release when compared to the conventional marketed formulation. SNEDDS also distributed higher towards the target site liver. Hence the formulation with Capryol 90 and Cremophor EL \& Ethanol can allow the use of the potent antimalarial Artesunate effectively in case of highrisk malarial patients.

\section{References}

1. Vieth M, Siegel MG, Higgs RE, Watson IA, Robertson DH, et al. (2004) Characteristic physical properties and structural fragments of marketed oral drugs. J Med Chem 47: 224-232.

2. Tang B, Chang G, Gu JC, Xu CH (2008) Development of solid self-emulsifying drug delivery systems: Preparation techniques and dosage forms. Drug Discov Today 13: 606-612.

3. Rasool AA, Anwar AH, Lewis WD (2002) Solubility enhancement of some water insoluble drugs in the presence of nicotinamide and related compounds. J Pharm Sci 80: 387-393.

4. Zhao L, Li P, Yalkowsky SH (1999) Solubilization of fluasterone. J Pharm Sci 88: 967-969.

5. Yohei K, Koichi W, Manabu NSY, Satomi O (2011) Formulation design for poorly water-soluble drugs based on biopharmaceutical classification system: Basic approaches and practical applications. Int J Pharm 420: 1-10.

6. Pouton CW (2000) Lipid formulations for oral administration of drugs: nonemulsifying, self-emulsifying and 'self-microemulsifying' drug delivery systems. Eur J Pharm Sci 11: S93-S98.

7. Narang AS, Delmarre D, Gao D (2007) Stable drug encapsulation in micelles and microemulsions. Int J Pharm 345: 9-25.

8. Hülsmann S, Backensfeld T, Keitel S, Bodmeier R (2000) Melt extrusion-an alternative method for enhancing the dissolution rate of 17 beta-estradiol hemihydrates. Eur J Pharm Biopharm 49: 237-242.

9. Ljusberg-Wahren $H$, Seier Nielsen $F$, Brogård M, Troedsson E, Müllertz A (2005) Enzymatic characterization of lipid-based drug delivery systems. Int J Pharm 298: 328-332

10. Abdalla A, Klein S, Mader K (2008) A new self-emulsifying drug delivery system (SEDDS) for poorly soluble drugs: characterization, dissolution, in vitro digestion and incorporation into solid pellets. Eur J Pharm Biopharm 35: 457-464. 
Citation: Kumar SR (2017) Artesunate Loaded Self Nanoemulsified Drug Delivery System: A Preliminary Study for Improved Efficacy in the Treatment of Malaria: Formulation, Characterization and Bio-Distribution Study. J Bioequiv Availab 9: 364-371. doi: 10.4172/jbb.1000326

11. Basalious EB, Shawky N, Badr-Eldin SM (2010) SNEDDS containing bioenhancers for improvement of dissolution and oral absorption of lacidipine I: development and optimization. Int J Pharm 391: 203-211.

12. Richard AH, Pamela CC (2009) Pharmacology (4th edn.) Lipinncott's Illustrated Reviews, Lipinncott Williams and Wilkins, Philadelphia, USA.

13. Tripathi KD (2008) Essential medical pharmacology ( $6^{\text {th }}$ edn.) Jaypee, New Delhi, India.

14. Bhavesh SB, Punit BP, Hetal KP, Mukesh CG, Pragna KS (2012) Microemulsion Based Gel of Terbinafine for the treatment of Onchomycosis: Optimization of Formulation using D-Optimal Design. AAPS Pharm Sci Tech 13: 184-192.

15. Shafiq S, Shakeel F, Talegaonkar S, Ali J, Baboota S, et al. (2007) Formulation development and optimization using nanoemulsion technique: A technical note. AAPS Pharm Sci Tech 28: E12-E17.

16. Seethala R, Fernandes PB (2001) Handbook of Drug Screening. Marce Dekker Inc., NY, USA 29: 597-601.

17. Elnaggar YS, El-Massik MA, Abdallah OY (2009) Self-nanoemulsifying drug delivery systems of tamoxifen citrate: design and optimization. Int J Pharm 380: 133-141.

18. Shah P, Bhalodia D, Shelat $P$ (2010) Nanoemulsion: A Pharmaceutical Review Syst Rev Pharm 1: 24-32.

19. Shafiq S, Shakeel F, Khar RK (2008) Enhanced stability of ramipril in nanoemulsion containing cremophor-EL: a technical note. AAPS Pharm Sci Tech 9: 1097-1101.

20. Ghosh PK, Majithiya RJ, Umrethia ML, Murthy RS (2006) Design and development of microemulsion drug delivery system of acyclovir for improvement of oral bioavailability. AAPS Pharm Sci Tech 7: 77.
21. Sushil K, Sushma TLM, Negi ZKI (2012) Design and Development of Ciclopirox Topical Nanoemulsion of Sublingual Onchomycoses. Ind J Pharm Educ Res 46: 303-311.

22. Date AA, Nagarsenker MS (2007) Design and evaluation of self-nanoemulsifying drug delivery systems (SNEDDS) for cefpodoxime proxetil. Int J Pharm 329: 166-172.

23. Sunesen VH, Pedersen BL, Kristensen HG, Müllertz A (2005) In vivo in vitro correlations for a poorly soluble drug, danazol, using the flow-through dissolution method with biorelevant dissolution media. Eur J Pharm Sci 24 305-313.

24. Jawahar N, Meyyanathan SN, Senthil V, Gowthamarajan K, Baruah U et al (2013) Improved oral bioavailability of PLGA-nanoparticles containing a typical antipsychotic agent. Int J Biol Pharmaceut Res 4: 938-945.

25. Aditya NP, Patankar S, Madhusudhan B, Murthy RSR, Souto EB (2010) Arthemeter-loaded lipid nanoparticles produced by modified thin-film hydration Pharmacokinetics, toxicological and in vivo anti-malarial activity. Eur $\mathrm{J}$ Pharmaceut Sci 40: 448-455

26. Singh KK, Vingkar SK (2008) Formulation, antimalarial activity and biodistribution of oral lipid nanoemulsion of primaquine. Int J Pharm 347: 136-143.

27. Kumar RS (2013) Design, development and evaluation of fenofibrate and rosuvastatin nanodroplets. Eur Sci J 4: 606-617.

28. Rizwan BK, Anil D, Jayasankar K, Chinni S, Manjunatha N (2014) Pharmacokinetics and tissue distribution of a M1 muscarinic acetylcholine receptor positive allosteric potentiator, benzyl quinolone carboxylic acid. Anal Methods 6: 2672-2678 